\title{
Comparación de los cambios químicos y microbiológicos en la maduración del queso Colonia salado tradicionalmente y por impregnación en vacío
}

\author{
Crosa, M. J. ${ }^{(1)}$, Harispe, R. ${ }^{(2)}$, Mussio, P. ${ }^{(1)}$, Pelaggio, R. ${ }^{(1)}$, Repiso, L. ${ }^{(1)}$, Silvera, C. ${ }^{(3)}$ \\ Contacto: mcrosa@latu.org.uy \\ (1) Laboratorio Tecnológico del Uruguay (LATU) - (2) Naturalia S.R.L - ${ }^{(3)}$ Universidad Católica del Uruguay Dámaso \\ Antonio Larrañaga (UCU). \\ Recibido: 3/07/2009 - Aprobado: 2/12/2009
}

\begin{abstract}
Resumen
El queso Colonia es un queso típico uruguayo, elaborado según los criterios de calidad y tradición quesera de inmigrantes suizos radicados en el departamento de Colonia. Su investigación y publicación aportan conocimiento para la difusión de un proceso que aún no presenta denominación de origen protegida. El objetivo del estudio fue investigar si la tecnología de salado por impregnación en vacío afecta el proceso de maduración del queso Colonia en comparación con el proceso de salado tradicional. Para el seguimiento de los cambios se realizaron determinaciones del índice de maduración, concentración del cloruro de sodio en agua del queso, el pH y la evolución de las bacterias Lactococcus lactis, Lactococcus lactis subsp. diacetylactis, Leuconostoc subsp. mesenteroides y Propionibacterium. Al finalizar la maduración, se evaluaron sensorialmente los atributos de textura, sabor y aroma, apariencia externa y apariencia interna. Las condiciones operativas elegidas del salado por impregnación en vacío lograron el mismo ingreso de sal que las del proceso tradicional y en la mitad del tiempo. No se observaron diferencias en ninguno de los parámetros químicos y microbiológicos estudiados. En lo sensorial tampoco se apreciaron diferencias en el flavor, textura y apariencia externa. Se hallaron ciertas diferencias en el tamaño y distribución de los ojos.

Palabras clave: Tiempo de salado, bacterias lácticas, bacterias propiónicas, queso uruguayo.
\end{abstract}

\begin{abstract}
$\underline{\text { Abstract }}$
"Colonia" type cheese is a typical Uruguayan cheese, elaborated following the quality standards and cheese making tradition brought by Swiss immigrants settled down at the Uruguayan department of Colonia. Its study and outreach provide knowledge to the diffusion of a process wich does not present a protected designation of origin. The aim of the study was to analize if the vacuum impregnation technology affects Colonia cheese ripening process compared with the traditional salting methods. Chemical, microbiological and sensory changes during ripening after both, SIV and traditional salting methods, were analized in this study. Chemical changes refer to moisture, sodium chloride concentration and rate of ripening. The microbiological changes were focused onto bacteria growing and identification of Lactococcus lactis, Lactococcus lactis subsp diacetylactis, Leuconostoc subsp mesenteroides and Propionic bacteria. Sensory attributes linked to texture, taste and flavor, as much as external and internal appearances were evaluated. The selected operating conditions of the vacuum impregnation process allowed the income ingress of salt to the cheese in half traditional process time. Under these conditions, no differences in chemical and microbiological parameters studied were appreciated. There were no sensory differences in flavor, texture and the outward appearance but certain differences in the size and distribution of the eyes were found.

Keywords: Time of salting, lactic acid bacteria, Propionic bacteria, Uruguayan cheese.
\end{abstract}

\section{Introducción}

El queso Colonia es un queso típico uruguayo, elaborado según los criterios de calidad y tradición quesera de los inmigrantes suizos radicados en la cuenca lechera del departamento de Colonia. El proceso tradicional de salado del queso Colonia de $7 \mathrm{~kg}$ ocurre por inmersión en salmuera concentrada $\left(20^{\circ} \mathrm{Bé}, 5,2 \mathrm{de} \mathrm{pH}, 10-12{ }^{\circ} \mathrm{C}\right.$ de temperatura) durante 48 horas. En estas condiciones, el ingreso de sal ocurre por difusión, con el tiempo de inmersión como única variable de control del proceso.

La tecnología de salado por impregnación en vacío fue ampliamente estudiada por Fito y colaboradores desde el año 1994 (Fito, 1994; Fito et al.,1993; Guamis, 1997; Pavia, 1999). En este mecanismo, la penetración de la sal en el queso se debe no sólo al proceso de acción capilar, sino también al gradiente de presión impuesto al sistema.

La aplicación de esta tecnología permite disminuir el tiempo de salado y controlar el ingreso de sal en el queso, mediante el monitoreo de los ciclos de presión de vacío versus tiempo y tiempo a presión atmosférica. Por otro lado, este proceso de salado podría afectar la microestructura del queso, la evolución de los fermentos microbianos $\mathrm{y}$, en consecuencia, la proteólisis (Pavia et al., 1999).

Pavia et al. (2000) estudiaron la proteólisis del queso tipo Manchego salado por impregnación en vacío. El proceso de salado afectó únicamente el grado de proteólisis en la cáscara del queso en comparación con el salado tradicionalmente.

La maduración del queso es un proceso mediante el cual la cuajada recién elaborada, de pobres características reológicas y sensoriales, se transforma en una masa homogénea con sabor, aroma y textura característicos. Ello se logra durante la maduración, por medio de cambios secuenciales y simultáneos causados por las proteinasas de la leche, las enzimas coagulantes y los cultivos iniciadores.

En este estudio se determinó el índice de maduración como indicador del grado de proteólisis, la difusión de cloruro de sodio en el queso, el valor del pH y la evolución de las bacterias Lactococcus lactis, Lactococcus lactis subsp. diacetylactis, Leuconostoc subsp. mesenteroides y de las bacterias propiónicas. Al finalizar la maduración, se evalúan sensorialmente los atributos de textura, sabor 
y aroma, apariencia externa y apariencia interna.

El objetivo del estudio fue investigar si la tecnología de salado por impregnación en vacío afecta el proceso de maduración del queso Colonia en comparación con el proceso de salado tradicional. No se reportan estudios publicados al respecto para el caso del queso Colonia; su estudio y publicación aportará datos relevantes para el desarrollo de esta tecnología en Uruguay.

\section{Materiales y Métodos}

\section{Descripción del proceso de elaboración del queso}

En la planta de elaboración de la empresa Naturalia S.R.L. se elaboró queso en tina de 1.100 litros de leche pasteurizada y estandarizada en su tenor graso en $2,7 \%$, utilizando fermento directo de bacterias lácticas y propiónicas y cuajo bovino líquido. La cuajada se cortó en granos medios de 6 a $7 \mathrm{~mm}$ de diámetro, se agitó durante 15 minutos a $32{ }^{\circ} \mathrm{C}$ y se coció a $48{ }^{\circ} \mathrm{C}$ durante 30 a 40 minutos. Posteriormente se pescó el cuajo y se pre-prensó, logrando 15 moldes para quesos de $7 \mathrm{~kg}$ peso final. Las unidades se prensaron durante cuatro horas y se salaron en salmuera. Una vez finalizado el proceso de salado, se mantuvieron en cámara de oreo de $7^{\circ} \mathrm{C}$ durante 12 horas y finalmente se pasaron a la cámara fría de maduración. Los quesos se mantuvieron 10 días en la cámara fría a $8{ }^{\circ} \mathrm{C}$ y $85 \%$ de humedad relativa y los 10 días siguientes en la cámara caliente a $20^{\circ} \mathrm{C}$ y $90 \%$ de humedad relativa. Finalizado el proceso de maduración, los quesos presentan un $25.5 \%$ de grasa en base húmeda, 4,15\% de nitrógeno total en base húmeda, $44 \%$ de humedad en base húmeda y $0,55 \%$ de cloruro de sodio en base húmeda.

El proceso de salado tradicional (TRAD) consiste en la inmersión de los quesos en salmuera 20 Bé de densidad y $10-12{ }^{\circ} \mathrm{C}$ durante 48 horas. El salado por impregnación en vacío (SIV) consistió en la inmersión de los quesos en la salmuera durante 20 horas a presión atmosférica, seguido por dos horas de cambios de presión por pulsos de vacío hasta $100 \mathrm{mmHg}$ y recuperación a la presión atmosférica durante una hora más. Esto suma un tiempo total del proceso de 24 horas.

\section{Diseño de la experiencia}

La experiencia se realiza por duplicado. Cada experiencia corresponde a una tina de 1.100 litros de leche, logrando 15 unidades de $7 \mathrm{~kg}$, de las cuales ocho fueron saladas por impregnación en vacío y las otras siete según proceso tradicional. El proceso de maduración fue el mismo en todas las unidades. Se registró diariamente la temperatura, introduciendo una sonda de temperatura hasta el centro geométrico de una pieza salada SIV y otra salada TRAD.

El estudio de la maduración se realizó tomando unidades enteras de queso de las cámaras de maduración en los días 3, 6, 10, 13 y 20 para su análisis. En la otra experiencia, los días de extracción fueron $2,6,10,13,21$. En cuatro de los cinco muestreos se toma una muestra del queso salado SIV y del TRAD y en uno de los muestreos se toman dos muestras de cada queso.

\section{Descripción de procedimientos analíticos}

El seguimiento de la temperatura del centro geométrico de los quesos fue diario. La sonda de pincho tipo $\mathrm{K}$ fue introducida $\mathrm{y}$ mantenida en el queso durante todo el proceso de maduración. El registro de la temperatura y humedad ambiente en las cámaras se realizó mediante un dattalogger Testo, ubicado cerca de los quesos en estudio.
La medida de $\mathrm{pH}$ fue con $\mathrm{pHmetro} \mathrm{tipo} \mathrm{de} \mathrm{penetración} \mathrm{Mettler} \mathrm{Toledo}$ inLab, siguiendo el protocolo de ensayo PEC.LACAM.LAC 006.

El nitrógeno total (\%NT) fue obtenido por disolución del queso en citrato de sodio 9,5 molar, el nitrógeno soluble se obtuvo en la solución de $\mathrm{pH} 4,6(\% \mathrm{NS})$ y el no proteico $(\% \mathrm{NNP})$, por disolución en $12 \%$ tricloroacético (TCA). La digestión se efectuó por método de Kjeldhal, según norma IDF 20B.

El porcentaje de cloruro de sodio fue determinado por titulación potenciométrica, según norma IDF 88. El porcentaje de humedad fue determinado siguiendo el método recomendado por norma IDF 4A.

Las determinaciones del \% $\mathrm{NaCl}$, del \% Humedad y del $\mathrm{pH}$ se realizaron en las zonas "centro", "medio" y "cáscara". La "cáscara" corresponde al primer centímetro y medio de la superficie del queso. El "centro" es la zona a un radio menor a 10 centímetros de distancia de la superficie y a $3 \mathrm{~cm}$ de distancia de la cara superior e inferior del cilindro, respectivamente. El "medio" es el resto del queso.

Se estimó la flora total del queso mediante recuento en PCA (Plate Count Agar - Difco), a $30{ }^{\circ} \mathrm{C}$ por 48 horas. El recuento de los Lactococcus fue por medio sólido M17 Agar (Difco) suplementado con un $10 \%$ de Lactosa, el cual se incubó a $30{ }^{\circ} \mathrm{C}$ por 48 horas. Este mismo medio se utilizó para el Streptococcus thermophilus, pero incubando a $42{ }^{\circ} \mathrm{C}$. La evolución de los Lactococcus lactis subsp. lactis var. diacetylactis se obtuvo por el medio diferencial Reddy's Differential Agar (Modified - HiMedia). Luego de cuatro días a $30^{\circ} \mathrm{C}$ se pueden diferenciar las colonias de Lactococcus lactis subsp. lactis var. diacetylactis por el consumo del citrato que crea un halo claro en el medio de cultivo. El recuento de Leuconostoc mesenteroides fue en MRS (de man, Rogosa, Sharpe - Oxoid) adicionado con vancomycina en una concentración de $30 \mu \mathrm{g} / \mathrm{ml}$ que se incubó a $25^{\circ} \mathrm{C}$ por 48 horas. El recuento de las bacterias propiónicas fue mediante el medio selectivo ALGA - PAL Propiobac (anaerobiosis, $30^{\circ} \mathrm{C}$ por seis días)

La evaluación sensorial se realizó con un panel integrado por siete expertos, en los atributos apariencia externa, apariencia interna, textura y flavor, según norma IDF 99C.

\section{Descripción del tratamiento estadístico de los datos}

Los ensayos químicos se realizaron por duplicado hasta lograr concordancia según el error analítico correspondiente a cada técnica. En un muestreo se contaron dos unidades del queso SIV y dos del queso TRAD; en esta instancia se determinó el intervalo de confianza al $95 \%$ de cada ensayo de cada experimento para un número de muestras igual a cuatro. Para los ensayos microbiológicos los recuentos fueron realizados por duplicado con una incertidumbre del laboratorio para recuento en PCA: 0,15 unidades logarítmicas.

\section{Resultados y Discusión}

\section{Registro de la historia térmica de las muestras}

En el Gráfico 1 se presentan la temperatura ambiente y la temperatura del centro geométrico del queso impregnado y del salado tradicionalmente tomadas cada 24 horas. Al finalizar el proceso de salado, la temperatura de los quesos fue de $13{ }^{\circ} \mathrm{C}$ y bajó a $8{ }^{\circ} \mathrm{C}$ (temperatura de cámara) luego de 24 horas de estadía. Cuando se cambian a cámara caliente, los quesos logran $18{ }^{\circ} \mathrm{C}$ luego de 60 horas de estadía, pero recién después de 120 horas se logra una temperatura en el centro del queso de $20{ }^{\circ} \mathrm{C}$. 


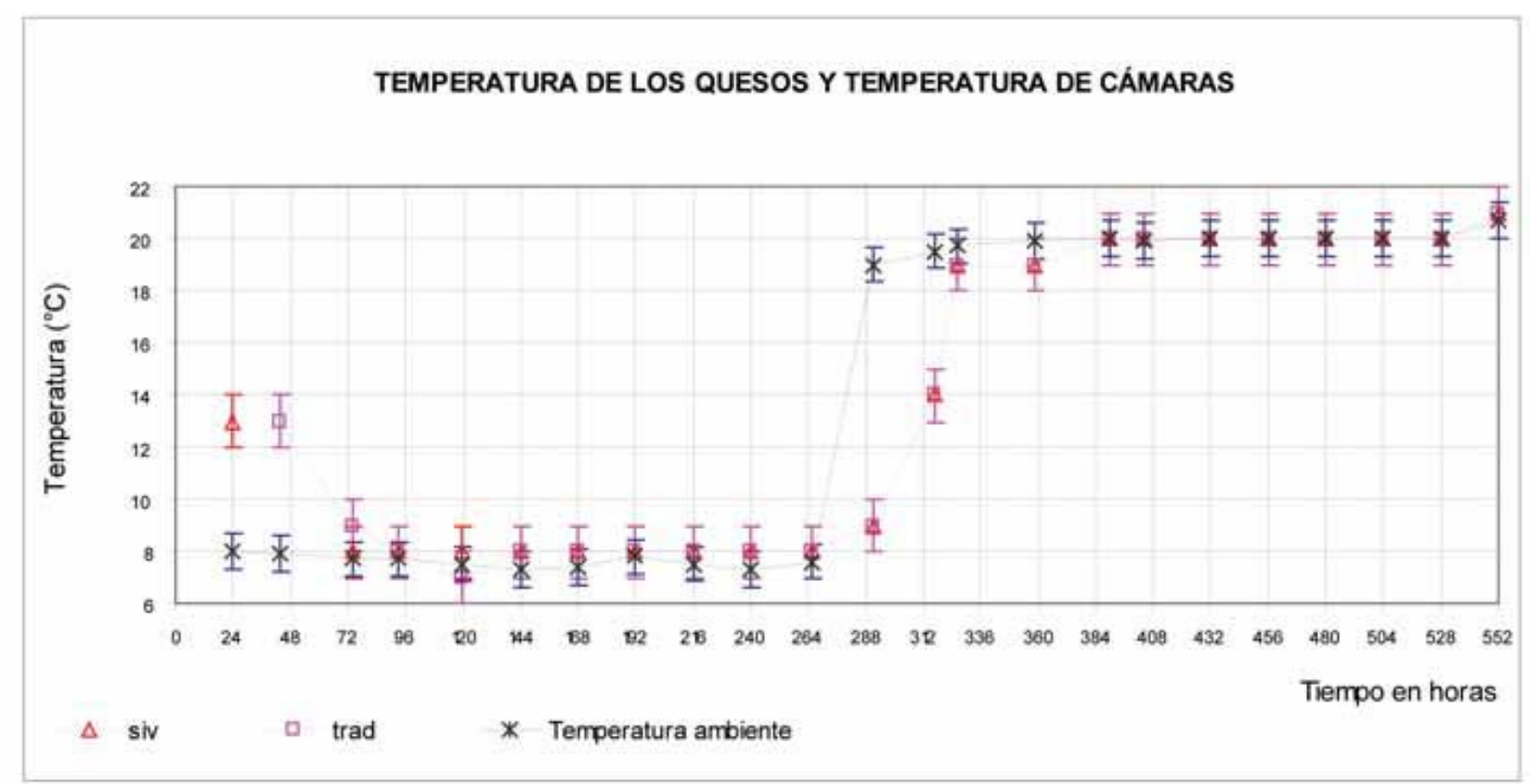

Gráfico 1. Seguimiento de temperatura de los quesos SIV y TRAD.

\section{Medida del pH}

En la Tabla 1 se presentan los valores de pH del centro, medio y cáscara de los quesos salados por TRAD y SIV.

\begin{tabular}{|c|c|c|c|c|c|c|}
\hline \multirow[b]{3}{*}{ DIA } & \multicolumn{6}{|c|}{ PH } \\
\hline & \multicolumn{3}{|c|}{ SIV } & \multicolumn{3}{|c|}{ ATM } \\
\hline & CENTRO & MEDIO & CASCARA & CENTRO & MEDIO & CASCARA \\
\hline 3 & 5,38 & 5,40 & 5,49 & 5,33 & 5,34 & 5,48 \\
\hline 6 & 5,38 & 5,44 & 5,52 & 5.38 & 5,39 & 5,50 \\
\hline 10 & 5,38 & 5,42 & 5,48 & 5,40 & 5,39 & 5,48 \\
\hline 13 & 5,34 & 5,39 & 5,53 & 5,34 & 5.41 & 5,58 \\
\hline 13 & 5,36 & 5,39 & 5,55 & 5,34 & 5,35 & 5,53 \\
\hline 21 & 5,34 & 5,37 & 5,53 & 5,34 & 5,37 & 5,48 \\
\hline PROMEDIO & 5,36 & 5,40 & 5,52 & 5,36 & 5,38 & 5,51 \\
\hline IC $95 \%$ & 0,03 & 0,04 & 0,04 & 0,04 & 0,04 & 0,06 \\
\hline
\end{tabular}

Tabla 1. Los datos informados corresponden al valor promedio de ambas experiencias. Se promedian los valores de $\mathrm{pH}$ en los diferentes días de maduración y se determina el intervalo de confianza con un $95 \%$ de significancia.

Los quesos SIV y TRAD no presentaron diferencias significativas (al $95 \%$ ) en los valores de pH. Tampoco se observa evolución alguna del pH en las tres zonas estudiadas durante la maduración. Pero se observan, en concordancia con otros estudios (Pavia, 2000), diferencias de la cáscara con el medio y centro del queso que están relacionadas con la diferencia de la concentración del cloruro de sodio en agua entre las zonas del queso.

\section{Proteólisis}

En el Gráfico 2 se expone la extensión de la proteólisis de los quesos TRAD y los SIV de las experiencias. Los quesos SIV no presentaron diferencias significativas al $95 \%$ con los TRAD en ninguno de los días de maduración analizados.

Existieron diferencias en la evolución de la proteólisis entre las experiencias. Los valores iniciales del \%NS/NT y de NNP/NT del batch 2 fueron mayores. Considerando que el porcentaje de nitrógeno total fue concordante en ambas experiencias, de $4.00 \pm 0,04 \%$, se puede adjudicar esta diferencia al poder proteolítico del cuajo agregado en tina. Sin embargo, se logra el mismo grado de avance de la proteólisis al final del proceso. 


\section{EVOLUCIÓN DEL ÍNDICE DE MADURACIÓN}

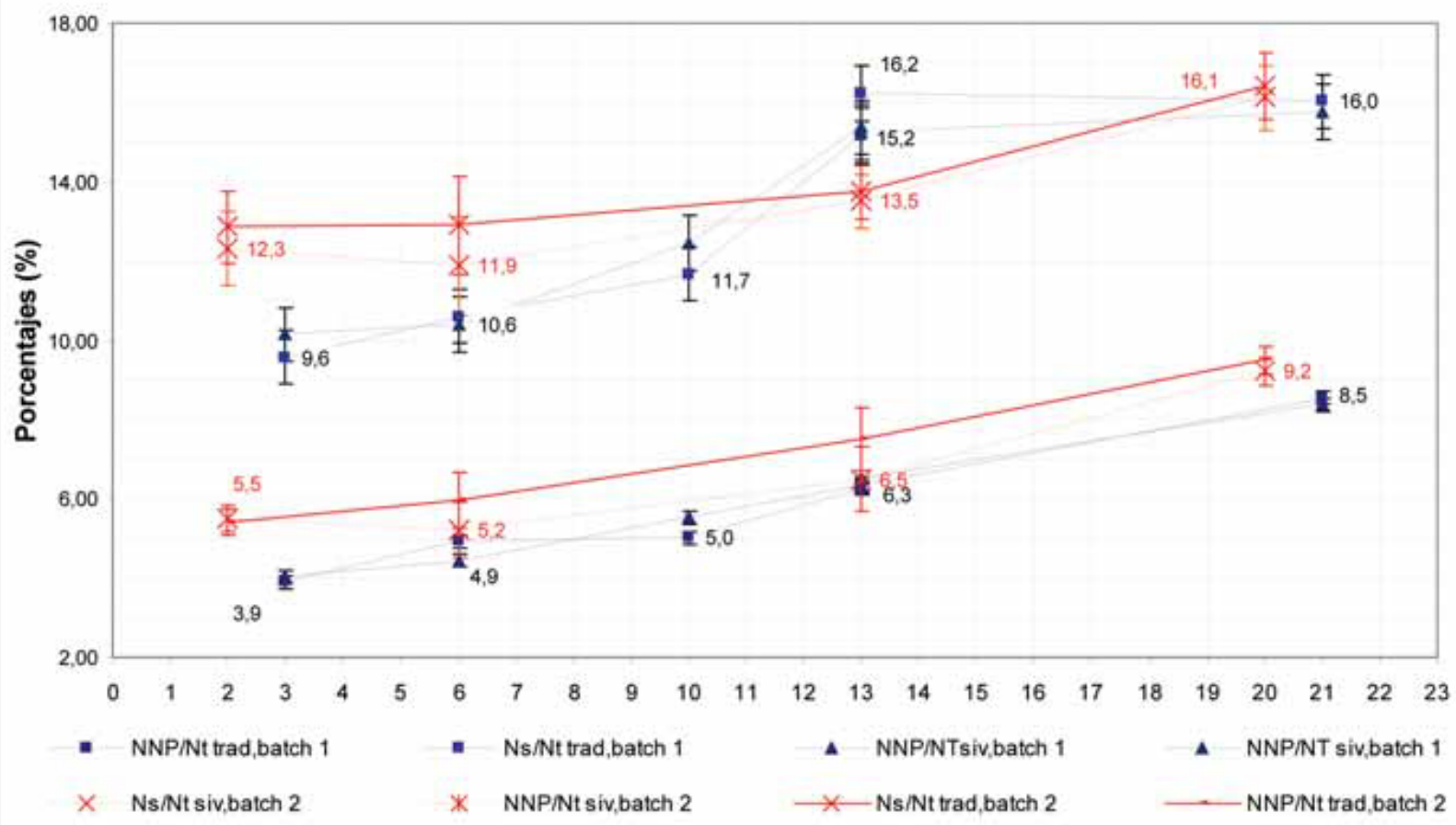

Gráfico 2. Evolución del \% nitrógeno soluble y en \% nitrógeno no proteico de los quesos salados tradicionalmente y de los quesos salados por impregnación en vacío, ensayo de ambas experiencias. El valor informado surge del promedio de los valores obtenidos de cada experiencia, aceptando concordancia cuando la diferencia absoluta es menor a 0.08 .

\section{Perfil de concentración de $\mathrm{NaCl} /$ agua}

En el Gráfico 3 se expresa la evolución de la concentración de cloruro de sodio en el agua contenida en la masa del queso salado tradicionalmente y por impregnación en vacío, de la cáscara, medio y centro del queso durante su maduración.

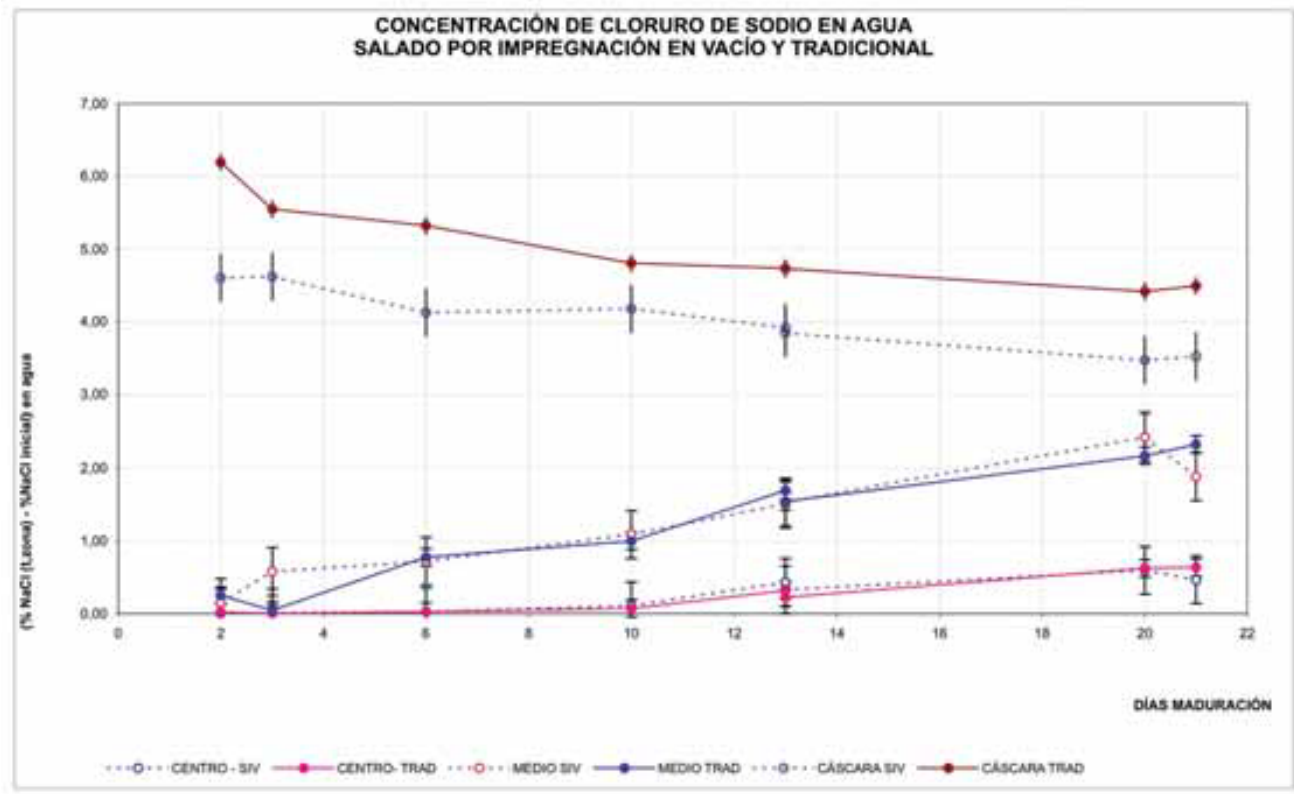

Gráfico 3. Evolución del cloruro de sodio en la cáscara, medio y centro en los diferentes días de maduración. Los valores informados en los días 6,10 y 13 corresponden al promedio de ambos batch. 
La concentración de sal en el centro y medio del queso no presentó diferencias significativas al $95 \%$ entro los salados por impregnados en vacío y los salados tradicionalmente. Pero en la cáscara el \% $\mathrm{NaCl} /$ agua de los quesos SIV fueron significativamente menores a los TRAD. Esto ocurre porque los pulsos de vacío aplicados afectan el ingreso de la sal en el centro y medio del queso, pero la concentración en la cáscara continúa dependiendo fuertemente del tiempo de salado (Crosa et al., 2008).

\section{Resultados microbiológicos}

En el Gráfico 4 se muestran los recuentos de Streptococcus termophilus en el queso salado tradicionalmente y en el queso con impregnación en vacío a lo largo del proceso de maduración. El número de Streptococcus termophilus no presenta diferencias significativas entre ambos quesos (SIV y TRAD).

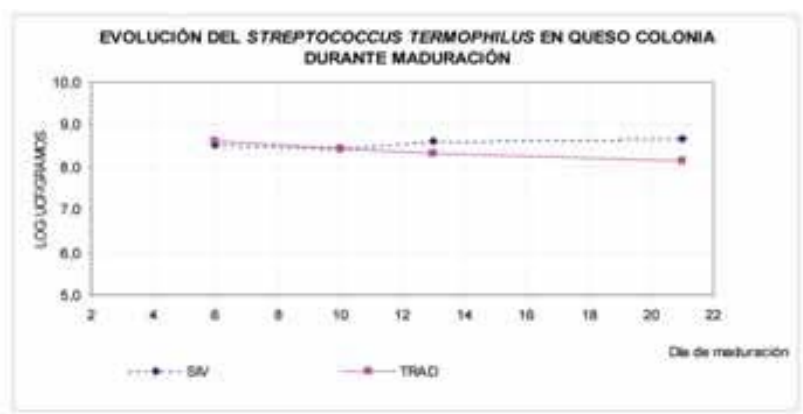

Gráfico 4. Recuento de Streptococcus termophilus. Recuentos realizad os por duplicado; incertidumbre del laboratorio para recuento en PCA: 0,15 unidades logarítmicas.

En el recuento de Lactococcus y Lactococcus diacetil lactis no se observaron diferencias en los quesos con distintas tecnologías de salado, presentando ambos un mismo perfil de crecimiento a lo largo del proceso de maduración (Gráfico 5).

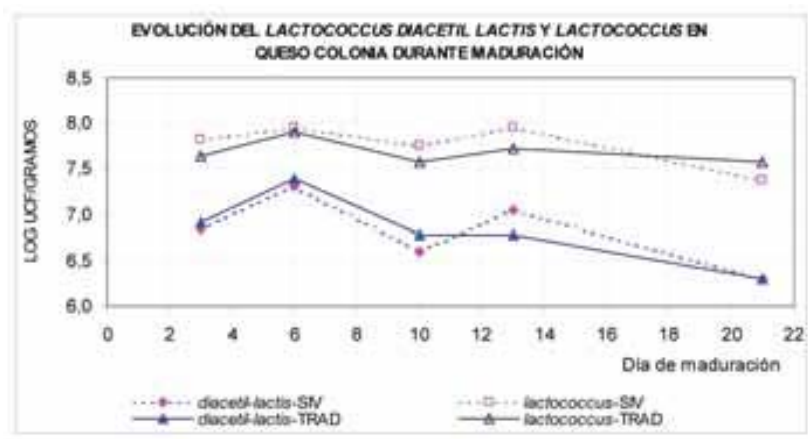

Gráfico 5. Recuento de Lactococcus y Lactococcus diacetil lactis. Recuentos realizados por duplicado; incertidumbre del laboratorio para recuento en PCA: 0,15 unidades logarítmicas.

Se observa una evolución ascendente, logrando un orden de diferencia, en el recuento de las bacterias Leuconostoc mesenteroides y de las bacterias propiónicas durante la maduración (Gráfico 6). Sin embargo, cabe destacar que no existieron diferencias significativas entre los quesos tradicionales e impregnados al vacío.

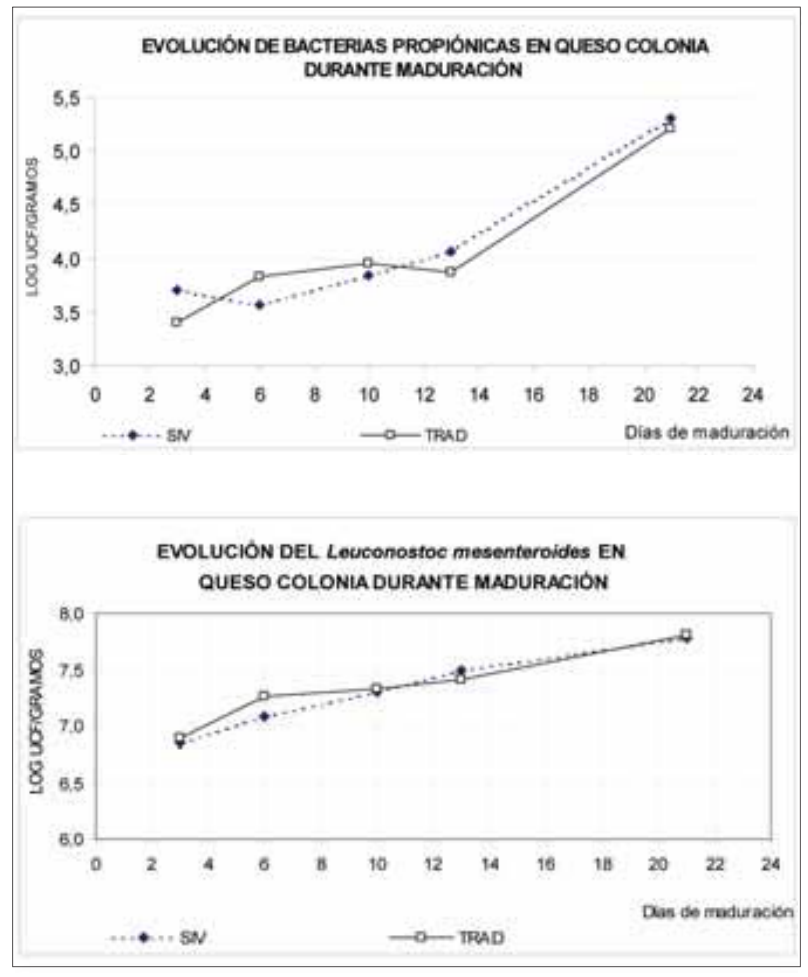

Gráfico 6. Recuento de Leuconostoc mesenteroides y bacterias propiónicas. Recuentos realizados por duplicado; incertidumbre del laboratorio para recuento en PCA: 0,15 unidades logarítmicas.

Al realizar el recuento de mesófilos totales en PCA a lo largo de la maduración se observaron valores del orden de $10^{8}$ durante todo el proceso en ambos quesos. Estos valores constantes y del orden de los obtenidos para los recuentos de los distintos fermentos lácticos, evidencian la no existencia de una fuente de contaminación externa que podría de algún modo interferir con el estudio realizado al competir con la flora en estudio.

\section{Evaluación sensorial}

En la Tabla 2 se presentan los puntajes asignados a cada atributo. Se detectaron diferencias en la apariencia interna pero no en los atributos de apariencia externa, textura y flavor, con un $95 \%$ de significancia.

La escala de evaluación utilizada fue:

5. Concordancia con el requisito sensorial preestablecido.

4. Mínima desviación del requisito sensorial preestablecido.

3. Desviación perceptible del requisito sensorial preestablecido.

2. Desviación considerable del requisito sensorial preestablecido.

1. Desviación muy considerable del requisito sensorial preestablecido.

\begin{tabular}{|l|c|c|c|c|}
\hline & \multicolumn{4}{|c|}{ ATRIBUTO } \\
\cline { 2 - 5 } & $\begin{array}{c}\text { Apariencia } \\
\text { MUterna }\end{array}$ & $\begin{array}{c}\text { Apariencia } \\
\text { interna }\end{array}$ & Textura & Flavor \\
\hline SIV & 68 & 148 & 134 & 193 \\
\hline IRADICIONAL & 62 & 122 & 126 & 180 \\
\hline
\end{tabular}

Tabla 2. Resultados del panel de evaluación sensorial.

La evaluación sensorial manifiesta diferencia en la apariencia interna de los quesos según el proceso de salado. Los ojos de los quesos impregnados son de menor tamaño y en un número mayor 
y se encuentran homogéneamente distribuidos en relación al queso tradicional. A continuación se presentan imágenes (Figuras 1 y 2) en las que se aprecian las diferencias detalladas.

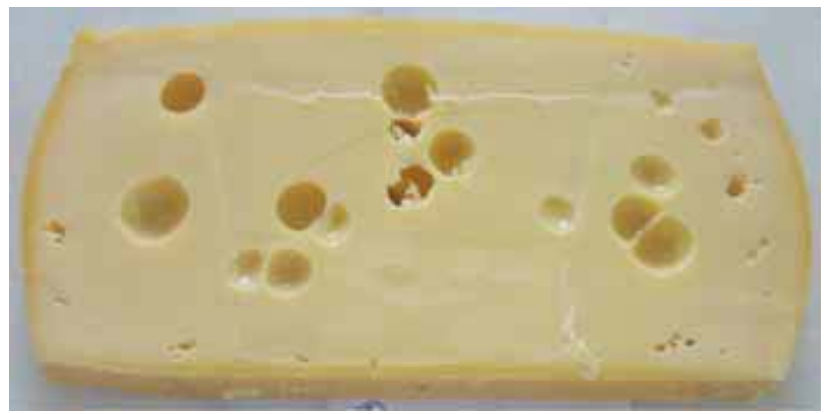

Figura 1. Queso salado tradicionalmente.

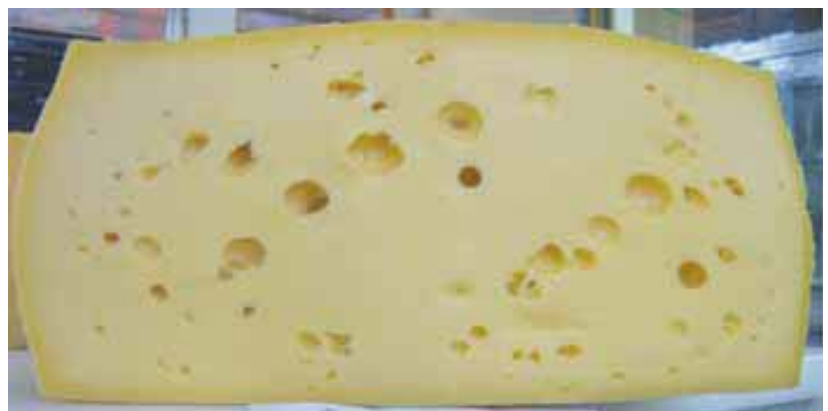

Figura 2. Queso salado por impregnación en vacío.

\section{Conclusiones}

No se apreciaron diferencias significativas en la extensión de la proteólisis, el $\mathrm{pH}$ y en la evolución de las bacterias del fermento estudiados en la maduración de los quesos salados tradicionalmente y por impregnación en vacío.

Se hallaron diferencias en la concentración del cloruro de sodio en la cáscara. La concentración del cloruro de sodio en agua de los quesos salados por impregnación en vacío fue menor a la de los quesos salados tradicionalmente, resultado coincidente con otros trabajos científicos (Pavia, 2000).

En lo sensorial no se observaron diferencias en el flavor, en textura, ni en la apariencia externa, aunque se apreciaron ciertas diferencias en el tamaño y distribución de los ojos.

\section{Reconocimientos}

- Programa de Desarrollo Tecnológico. Ministerio de Educación y Cultura de Uruguay, por su financiamiento para el desarrollo de las experiencias.

- Téc. Lech. Pablo Wurth, Jefe de Planta de Elaboración, Naturalia S.R.L.

- Bach. Quím. M. Inés Dios, analista de laboratorio, por su apoyo analítico.

- Departamento de Microbiología, Departamento de Análisis químicos de productos Lácteos, Cárnicos y de la Colmena y Departamento de Biotecnología del LATU.

\section{Referencias}

- CHIRALT, A.; FITO, P. Salting of Manchego type cheese by vacuum impregnation. En: FITO, P.; ORTEGA, E.; BARBOSA, G. Food Engineering 2000. New York: Chapman \& Hall, 1997. pp.214-230.

- CROSA, M.J.; HARISPE, R.; REPISO, L.; SILVERA, C.

WURTZ, P. Mejoras para el tiempo de salado de quesos en más de un $50 \%$ del tiempo total. Uruguay. Dirección Nacional de la Propiedad Industrial. 31312. 2008-08-28.

- CROSA, M.J.; HARISPE, R.; REPISO, L.; SILVERA, C.; WURTZ, P. Sistema que acelera el ingreso de solutos en alimentos porosos. Uruguay. Dirección Nacional de la Propiedad Industrial. 31620. 2009-01-30.

- ECK, A. El Queso. Barcelona: Omega, 1990.

- FUENTES, C. Salado de quesos tipo Manchego: Aplicación de la impregnación a vacío y evolución de los compuesto volátiles durante la maduración. Valencia: Universidad Politécnica de Valencia, 1999. (Tesis Doctoral).

- GAUNA, A. Elaboración de quesos de pasta semidura con ojos. En: Cuaderno Lactológico. 2005, (3):1-81.

- GONZÁLEZ-MARTÍNEZ, C.; FUENTES, C.L.; CHIRALT, A.; ANDRÉS, A.; FITO, P. Effectiveness of vacuum impregnation brining of Manchego type curd. En: International Dairy Journal. 1999, (3):143-148.

- GUAMIS, B.; TRUJILLO, J.A.; FERRAGUT, V.; CHIRALT, A.; ANDRÉS, A.; FITO, P. Ripening control of Manchego type cheese salted by brine vacuum impregnation. En: International Dairy Journal. 1997, (7):185-192.

- INTERNATIONAL DAIRY FEDERATION (Belgium). IDF 4A: Cheese and processed cheese: determination of the total solids content (Reference Method). Brussels: IDF, 1982.

- INTERNATIONAL DAIRY FEDERATION (Belgium). IDF 99C: Sensory evaluation of dairy products by scoring: reference method. Brussels: IDF, 1997.

- INTERNATIONAL DAIRY FEDERATION (Belgium). IDF 20B: Milk: determination of nitrogen content. Brussels: IDF, 2001.

- INTERNATIONAL DAIRY FEDERATION (Belgium). IDF 88: Cheese and processed cheese products - Determination of chloride content: potentiometric titration method. Brussels: IDF, 2004.

- PAVIA, M.; TRUJILlO, J.A.; GUAMIS, B.; CAPELLAS, M.; FERRAGUT, V. Changes in microstructural, textural and colour characteristics during ripening of Manchego type cheese salted by brine vacuum impregnation. En: International Dairy Journal. 1999, (9):91-98.

- PAVIA, M.; TRUJILLO, A.J.; GUAMIS, B.; FERRAGUT, V. Proteolysis in Manchego type cheese salted by brine vacuum impregnation. En: Journal of Dairy Science. 2000, 83(7):14411447.

- VÁZQUEZ, S.; LOPRETTI, M. Estudio de cepa nativa y genéticamente modificada en microorganismos de la industria láctea. Montevideo: Facultad de Ciencias, 2004. (Tesis de Grado). 